\title{
The scourge of tuberculosis revisited
}

$\mathrm{T}$ HE RE-EMERGENCE OF TUBERCULOSIS AS A GLOBAL PUBLIC health concern has been underscored by rising incidence rates, particularly in human immunodeficiency virus (HIV) positive individuals and in the homeless and by recent outbreaks of multidrug-resistant tuberculosis in the United States (1-4). According to the World Health Organization (WHO) tuberculosis is one of the world's most neglected health problems, responsible for an estimated 3 million deaths per year, which is more than all other infectious diseases combined. It is further estimated that one in every three people in the world harbours the causative agent, Mycobacterium tuberculosis. Long a scourge in developing countries in Central and South America, Africa and Southeast Asia, with an estimated caseload of 5.5 million to 6.0 million (5) in 1990, the resurgence of tuberculosis in developed countries serves as a rude awakening to the predictions of the demise of tuberculosis in industrialized nations by the year 2010. Several European nations are experiencing an increase in tuberculosis, with Denmark, The Netherlands, Ireland, Norway, Italy and Switzerland reporting increases of between 10 and $33 \%$ in the number of cases of active tuberculosis between 1987 and 1991. After a steady decline over a period of three decades, there was a $20 \%$ increase in the number of reported cases of tuberculosis between 1985 and 1992 in the United States (6). This figure translates to roughly 39,000 more cases than had been expected, which is a remarkable number considering that tuberculosis had been declining by roughly $6 \%$ a year for over three decades. Most new cases have occurred in relatively young adults infected with HIV, in the homeless, the poor or in ethnic minorities. Ethnic minorities accounted for $70 \%$ of all tuberculosis cases reported to the Centers for Disease Control and Prevention (CDC) in 1991, while $27 \%$ involved people born outside the country. The percentage of American cases among the foreign-born, especially Hispanics, has been increasing every year. New York City with its large immigrant, HIV and homeless populations has experienced a doubling of tuberculosis cases since 1986. Tuberculosis has also emerged in the United States prison system, where the incidence is four times higher than in comparable age-matched nonprison populations.

The epidemiology of tuberculosis in Canada differs from that in many other industrialized countries since it is one of the few countries reporting fewer than 10 cases per 100,000 population (7). Approximately 1900 to 2100 new cases have been identified per year in Canada since 1987. The number of newly identified cases of tuberculosis has remained relatively static in Canada over the past seven to eight years. The number of cases occurring in Aboriginal and foreign-born individuals has remained stable or increased slightly, whereas the number of cases occurring in non-Aboriginal Canadianborn persons has decreased. The resurgence of tuberculosis in industrialized nations has been purported to be due to many factors, including rapid and accessible travel between countries, increasing numbers of cases in foreign-born persons from countries with high tuberculosis rates, and increasing numbers of individuals co-infected with HIV and latent tuberculosis.

HIV infection has emerged as one of the strongest predictors that latent tuberculosis will progress. The presence of HIV infection has been found to raise the relative risk of developing active tuberculosis from a 5 to $10 \%$ life-time risk to $8 \%$ per year (8). The overlap between populations with HIV infection and tuberculosis is unknown but the degree of overlap will have a profound effect on the future incidence of HIV-related tuberculosis. In the United States it is estimated that there are 10 million to 15 million persons infected with $M$ tuberculosis and one million infected with HIV. The pooled HIV seroprevalence from several large urban tuberculosis clinics in the United States increased from 13 to $22 \%$ between 1989 and 1992 (9). Fortunately, the number of persons in Canada with HIV infection with pulmonary tuberculosis is small at present at $1.5 \%$ of all reported AIDS cases.

The recent emergence of multidrug-resistant tuberculosis in hospitals, prisons and homeless shelters in the United States $(4,10-15)$ may present one of the most threatening features of the resurgence of tuberculosis. One of the earliest reports (10) described 87 patients with multidrug-resistant tuberculosis in four hospitals in New York City and Florida, and was associated with a high mortality and a short interval from diagnosis to death. Subsequent studies $(4,11-15)$ have also consistently reported a high mortality rate (50 to $90 \%$ ), a short median survival time and nosocomial transmission to health care workers. These studies have suggested that delays in diagnosis, late recognition of drug resistance, poor compliance with medications and lack of appropriate infection control precautions may have been contributing factors in nosocomial transmission.

Halting the resurgence of tuberculosis will require a concerted effort by many health care organizations and health 
care personnel. The WHO has proposed an ambitious global plan to curb the death rate from tuberculosis by $50 \%$ over the next decade. It is recommending that funds be set aside for underdeveloped countries to buy microscopes to aid in early identification, medications for treatment and for the institution of patient tracking programs (1). The WHO is stressing the treatment of known cases along with intensive follow-ups to ensure treated persons are cured. The $\mathrm{CDC}$ has also provided a number of recommendations for the prevention of transmission of tuberculosis in health care facilities, treatment guidelines and prophylaxis guidelines with specific reference to the management of multidrug-resistant tuberculosis (16-19). Several guidelines with respect to the diagnosis, prevention and control of tuberculosis in Canada have been recently published (20-22) and the Guidelines for the Prevention of Transmission of Tuberculosis in Canadian Health Care Facilities will be published shortly by Health Canada. A specific element of the treatment guidelines that may offer a potential solution to noncompliance with its attendant risk of development of drug resistance is the use of directly observed therapy (or DOT) which was reviewed recently in the Journal (23).

The guidelines, which are available from several organizations, will serve as a template for the new directions that have been set, but it is only through a multipronged multidisciplinary approach by health care personnel that the renewed scourge of tuberculosis will be halted. Efforts must clearly be directed towards the earliest possible diagnosis, prompt initiation of appropriate chemotherapy, appropriate isolation and screening of high risk populations.

\section{REFERENCES}

1. Centers for Disease Control and Prevention. Tuberculosis morbidity - United States, 1992. MMWR 1993;42:696-7,703-4.

2. Snider DE, Roper WL. The new tuberculosis. N Engl J Med 1992;326:703-5.

3. Brodney K, Dobkin J. Resurgent tuberculosis in New York City: human immunodeficiency virus, homelessness, and the decline of tuberculosis control programs. Am Rev Respir Dis 1991;144:745-9.

4. Daley CL, Small PM, Schecter GF. An outbreak of tuberculosis with accelerated progression among persons infected with the human immunodeficiency virus: an analysis using restriction-fragment-length polymorphisms. N Engl J Med 1992;326:231-5.

5. WHO Report: TB - A Global Emergency. Geneva: World Health Organization, 1993.

6. Centers for Disease Control and Prevention. Initial therapy for tuberculosis in the era of multidrug- resistance: recommendations of the Advisory Council for the Elimination of Tuberculosis. MMWR 1993;42:1-8.

7. Statistics Canada Catalogue 82-220. Tuberculosis Statistics 1993. Ottawa: Statistics Canada, 1995.
8. Onorato I, McCombs S, Morgan M, McCray E. HIV infection in patients attending tuberculosis clinics, United States, 1988-1992. 33rd Interscience Conference on Antimicrobial Agents and Chemotherapy (ICAAC), New Orleans, October 17-20, 1993. (Abstract \#1363)

9. Selwyn PA, Hartel D, Lewis VA, et al. A prospective study of the risk of tuberculosis among intravenous drug users with human immunodeficiency virus infection. N Engl J Med 1989;320:546-50.

10. Centers for Disease Control. Nosocomial transmission of multidrug-resistant tuberculosis among HIV-infected persons, Florida and New York 1988-1991. MMWR 1991;40:585-91.

11. Beck-Sague C, Dooley SW, Hutton MD, et al. Hospital outbreak of multidrug-resistant Mycobacterium tuberculosis infections: factors in transmission to staff and HIV-infected patients. JAMA 1992;268:1280-6.

12. Centers for Disease Control. Drug-resistant tuberculosis among the homeless - Boston. MMWR 1985;29:429-31.

13. Centers for Disease Control. Transmission of multidrug- resistant tuberculosis from an HIV-positive client in a residential substance-abuse treatment facility. MMWR 1991;40:129-31.

14. Dooley SW, Villarino ME, Lawrence M, et al. Nosocomial transmission of tuberculosis in a hospital unit for HIV-infected patients. JAMA 1992;267:2632-5.

15. Edlin BR, Tokars JI, Grieco MH, et al. An outbreak of multidrug-resistant tuberculosis among hospitalized patients with the acquired immune deficiency syndrome. N Engl J Med 1992;326:1514-21.

16. Centers for Disease Control. Guidelines for preventing the transmission of Mycobacterium tuberculosis in health care facilities, 1994. MMWR 1994;43(No. RR-13).

17. Centers for Disease Control and Prevention. National action plan to combat multidrug-resistant tuberculosis. MMWR 1992;41:1-48.

18. Centers for Disease Control. Screening for tuberculosis and tuberculous infection in high risk populations: recommendations of the Advisory Committee for Elimination of Tuberculosis. MMWR 1990;39:1-8.

19. American Thoracic Society/Centers for Disease Control. Treatment of tuberculosis and tuberculosis infection in adults and children. Am J Respir Crit Care Med 1994;149:1359-74.

20. Tuberculosis Committee, Canadian Thoracic Society. Essentials of tuberculosis control for the practicing physician. Can Med Assoc J 1994;150:1561-71.

21. Infectious Diseases and Immunization Committee, Canadian Pediatric Society. Short-course therapy for tuberculosis in infants and children. Can Med Assoc J 1994;150:1233-9.

22. Ad Hoc Committee for the Guidelines for Preventing the Transmission of Tuberculosis in Canadian Health Care Facilities and other Institutional Settings, Health Canada. Guidelines for Preventing the Transmission of Tuberculosis in Canadian Health Care Facilities and other Institutional Settings. (In press)

23. Shafran SD, Conly JM. Dash for DOT. Can J Infect Dis 1995;6:233-5.

JM Conly MD FRCPC Toronto, Ontario $S D$ Shafran MD FRCPC Edmonton, Alberta 


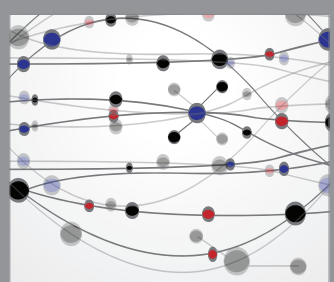

The Scientific World Journal
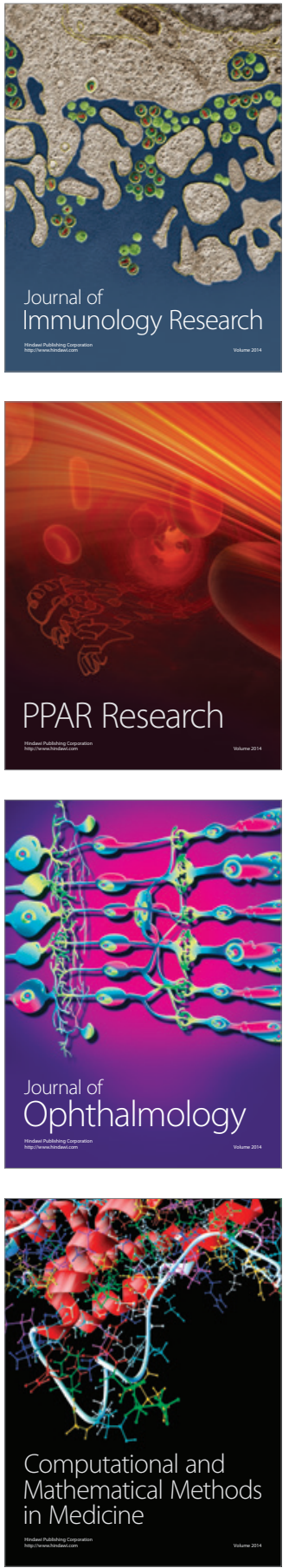

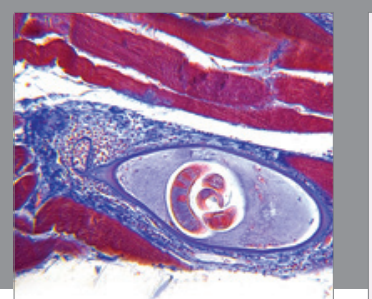

Gastroenterology Research and Practice

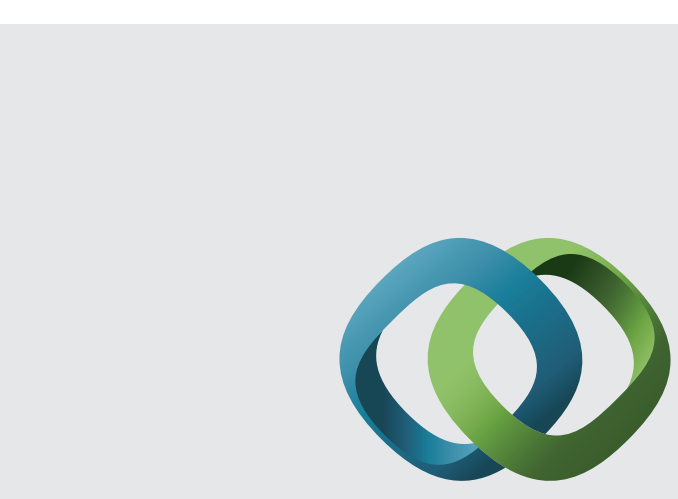

\section{Hindawi}

Submit your manuscripts at

http://www.hindawi.com
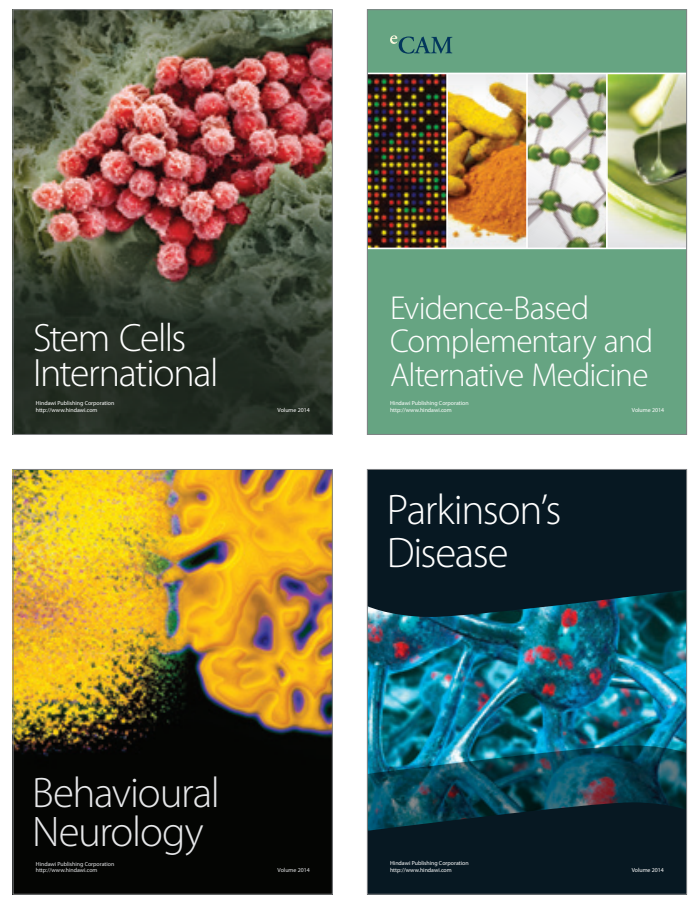
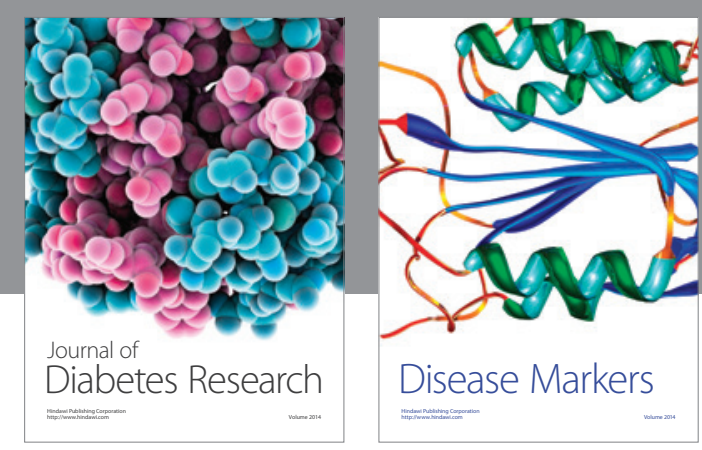

Disease Markers
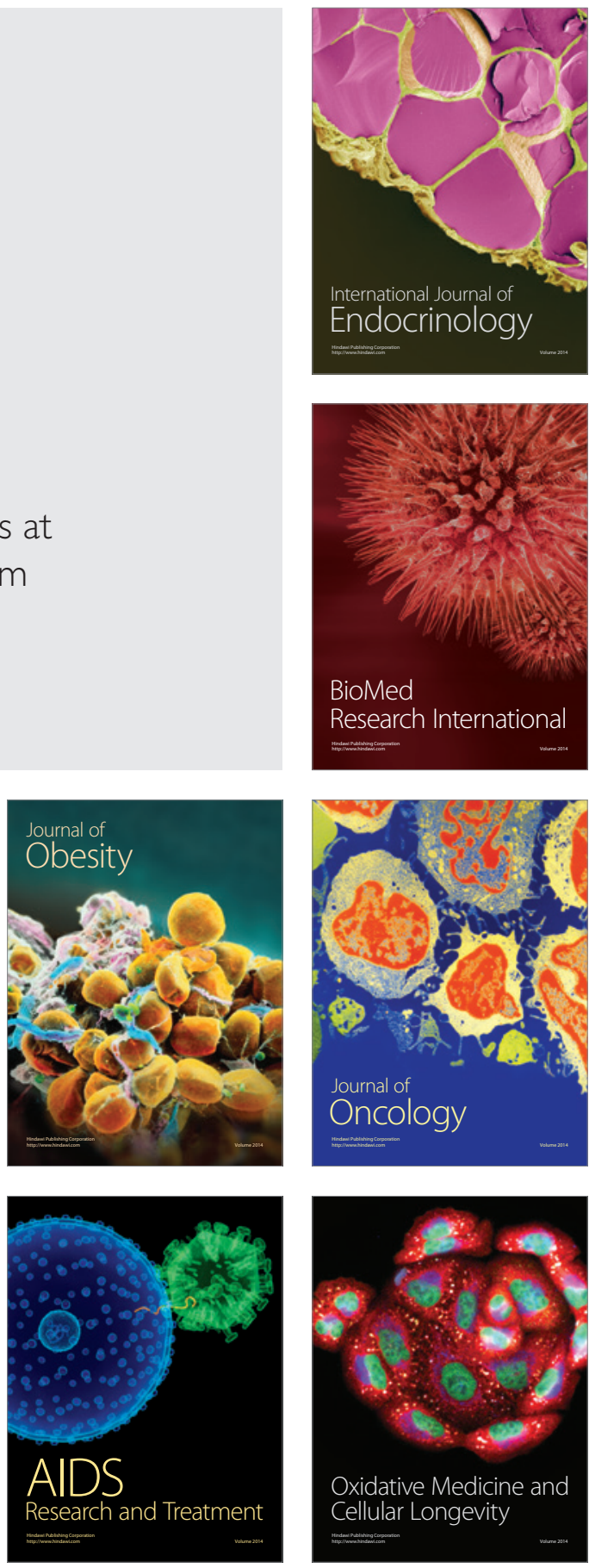